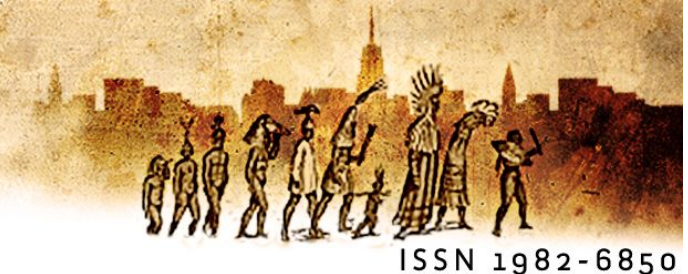

\title{
As concepções de leitura de professores em formação inicial e continuada: encontros ou desencontros?
}

\author{
Monica de Sousa Serafimi (UFC)
}

\begin{abstract}
Resumo: Este trabalho tem por objetivo mostrar quais as concepções de leitura dos professores em formação inicial e continuada. A fim de vislumbrarmos quais são essas concepções e suas implicações, utilizaremos como postulados teóricos as contribuições de Braggio (1992), Martins (1992), Leffa (1996), Bronckart (2003, 2006), Clot (1999, 2006) e Cicurel (1974, 1996, 2001). A metodologia utilizada consistiu em uma entrevista com 25 professores em formação inicial e de 25 professores em formação continuada. A entrevista foi do tipo estruturada, contendo 10 perguntas. O resultado desta pesquisa nos mostrou que a concepção de leitura dos professores em formação inicial é mais voltada para uma concepção interativa de leitura ao passo que os professores em formação continuada tendem a ver a leitura enquanto um processo de decodificação e interpretação única do texto. Isso nos permitiu concluir que é cada vez mais urgente a necessidade de motivar os professores das escolas para modificar as práticas, de dar condições para que outras práticas sejam adotadas e de se investigar por que nos novos tempos velhas práticas ainda permanecem.
\end{abstract}

Palavras-chave: Concepções de Leitura; professores em formação inicial; professores em formação continuada.

Abstract: This work aims to show that teachers' conceptions of reading in initial and continuing education. In order to see what these concepts and their implications are, we will use as theoretical postulates the contributions of Braggio (1992), Martins (1992), Leffa (1996), Bronckart (2003, 2006), Clot (1999, 2006) e Cicurel $(1974,1996,2001)$. The methodology used consisted of an interview with 25 teachers in initial training and 25 teachers in continuing education. The interview was the structured type, containing 10 questions. The result of this research has shown that the design of initial training for teachers of reading is more focused on an interactive conception of reading while teachers in continuing education tend to see reading as a process of decoding and unique interpretation of the text. This allowed us to conclude that it is ever more urgent the need to motivate teachers of schools to modify the practice of giving conditions for other practices are adopted and to investigate why the new times old practices still remain.

Keywords: Reading Conceptions; teachers in initial training; teachers in continuing education. 


\section{Palavras iniciais}

A leitura é um dos grandes objetivos almejados por todos aqueles envolvidos no processo de ensino-aprendizagem: pais, professores, gestores e alunos. Aos primeiros, a importância incide sobre o domínio do código ao final da alfabetização, afinal um grande investimento foi feito ao longo de todo um ano; aos gestores, a importância deve-se às constantes avaliações feitas pelos órgãos reguladores da educação; aos professores, a importância deve-se a uma espécie de prestação de contas aos pais dos discentes sobre o tempo passado na sala de aula; e aos últimos a importância incide sobre uma demanda ainda maior: mostrar aos pais, aos professores e a si mesmos o resultado de tanto investimento e esforço. No entanto, esta cobrança, na maioria das vezes, centra-se apenas no domínio do código, o que caracteriza uma concepção bastante equivocada sobre leitura.

Segundo Curto et al (2000), ler consiste na interpretação e adivinhação sobre o que o outro quer nos dizer, extrapolando, portanto, a ideia da relação direta entre leitura e decodificação.

Sobre o vínculo entre decodificação e compreensão textual, o autor (op. cit.; p.47) nos diz que decifrar sem compreender é um sintoma de hábitos prejudiciais, em que se separou o mecânico do compreensivo (...) Ler é compreender um texto. Compreender é um ato cognitivo, ou seja, o resultado de uma atividade mental.

Assim, a leitura é compreensiva na medida em que lemos de forma ativa, ou seja, quando somos capazes de antecipar interpretações, reconhecer significados e identificar erros e dúvidas.

Estas considerações sobre o que é ler permitem-nos refletir sobre os principais modelos de leitura para que, assim, possamos conhecê-los e avaliarmos qual desses modelos predomina nas turmas participantes desta pesquisa.

\section{As concepções de leitura: algumas considerações}

O modelo mais antigo de leitura, segundo Chartier (2001), é o modelo mecanicista de leitura, criado na Antiguidade clássica pelos gregos e romanos e que pode ser caracterizado por três passos: primeiro, decorar o alfabeto; depois, soletrar e, por último, decodificar palavras isoladas, frases até chegar ao texto. 
Para Samuels e Kamil (1988), somente em meados dos anos 6o os estudos sobre os modelos de leitura foram sistematizados: até essa época o que se sabia sobre leitura baseava-se na tradição filosófica.

O primeiro modelo de leitura, o modelo mecanicista, surgiu, de forma mais sistemática, em meados dos anos 6o, apoiado na postura estruturalista de língua e na Psicologia Behaviorista, e privilegiou o modelo ascendente de leitura (bottom up), aquele em que o autor deve extrair o significado apenas daquilo que se encontra na superfície do texto. Desse modo, a interpretação acontece do texto para o leitor, já que é unicamente no texto que o significado está. Podemos citar como exemplos desta concepção de leitura o modelo serial de Gough, e o processamento automático de La Berge e Samuels. Ambos os modelos se caracterizam por limitarem-se à microestrutura textual, não reconhecendo a participação do contexto na compreensão do significado.

Tal concepção mostrou-se bastante limitada, pois não refletia a inter-relação existente entre leitor e texto no momento da leitura e também porque não tinha como explicar fenômenos como o uso de inferências e a formulação de hipóteses que o leitor utiliza para construir o sentido daquilo que lê. Além disso, a leitura, vista sob este prisma, limita-se apenas a decodificação. Consequentemente, o bom leitor é aquele que compreende o que lê porque tem a capacidade de decodificar o texto completamente.

Esta visão de leitura, conforme Kleiman (1993), pode ser caracterizada por um fluxo unidirecional da informação, no qual o estímulo vem do texto para o leitor, que decodifica o texto de acordo com uma sequência pré-estabelecida de eventos perceptuais que vão desde a percepção de elementos grafofônicos até a unificação destes elementos formando frases.

Segundo Scaramucci (1995), embora esse modelo não faça referência à função do contexto, podemos inferir que ele é visto de modo estreito, como um contexto que considera apenas os elementos do texto ou seu cotexto.

Leurquin (2001) amplia as críticas feitas acima ao modelo mecanicista de leitura, elencando alguns problemas acarretados pelo uso, ainda persistente, deste modelo:

a) O aluno, se não reconhece uma palavra, interrompe a leitura do texto;

b) O texto possui apenas um sentido;

c) As ideias do texto são inquestionáveis;

d) A leitura é uma prática individual. 
Tais problemas mostram-nos que o ensino-aprendizagem é repetitivo, não concebendo, portanto, aluno e professor como sujeitos ativos na construção do conhecimento.

As lacunas deixadas pelo modelo mecanicista de leitura fizeram surgir estudos que vissem o processo de leitura centrado não apenas no texto, mas sim na figura do leitor. Surge, então, o modelo psicolinguístico de leitura. Desse modelo de leitura trataremos a seguir.

\subsection{O modelo psicolinguístico}

Opondo-se ao modelo mecanicista de leitura, temos o modelo psicolinguístico ou modelo descendente de leitura - top down- que privilegia o leitor como elemento principal no processo de leitura.

O surgimento deste modelo de leitura é resultado da mudança de paradigma na Linguística, do empirismo para o racionalismo, cujo foco é o leitor e sua atividade mental. Esse novo modo de ver a leitura apoiou-se também na Gramática GerativoTransformacional, opondo-se ao modelo tradicional de leitura, que se baseava no Estruturalismo norte-americano de Bloomfield e no Behaviorismo.

Este modelo foi defendido por Goodman (1988, p.12), para quem a leitura é

um processo receptivo da linguagem. É um processo psicolinguístico no qual começa com uma representação da superfície linguística codificada por um escritor e termina com o significado que o leitor constrói. Há, dessa maneira, uma interação essencial entre linguagem e pensamento na leitura. $O$ escritor codifica pensamento em linguagem e o leitor codifica linguagem em pensamento.

Goodman (op. cit), em seus primeiros estudos sobre leitura, baseou-se nos postulados de Chomsky, admitindo que o leitor possuísse capacidade de predizer, confirmar ou refutar aquilo que lê. Além disso, acreditava que o principal objetivo do leitor é, baseado em seu conhecimento prévio, atribuir significados que vai dele ao texto.

Nos anos 70, esta primeira abordagem de Goodman foi expandida, contemplando, a partir de então, a semântica à realidade do aluno. Assim, o autor passou a considerar que a 
leitura inicia-se com a imagem gráfica, que o objetivo da leitura é a compreensão e que os significados são reconstruídos pelo leitor durante o processo da leitura.

A partir do processamento descendente de leitura ou do jogo psicolinguístico de adivinhação, começou-se a atribuir grande importância aos processos cognitivos pelos quais passam os leitores antes e depois da leitura, o que justifica a preocupação dos seguidores deste modelo com a contextualização prévia da obra, a fim de ativar as regiões do cérebro responsáveis pelo processamento das informações, facilitando, assim, a interpretação do texto pelo leitor.

Para o modelo psicolinguístico, o contexto, ao contrário do modelo ascendente, tem grande importância para o leitor realizar inferências e para extrair as intenções do autor. Assim, segundo Scaramucci (1995), o componente linguístico assume um papel secundário, pois pode ser compensado por meio da ativação de esquemas do conhecimento de mundo, do assunto, do texto e do nível de proficiência linguística do leitor.

O modelo psicolinguístico de leitura manteve-se em alta até o início dos anos 80, quando começou a ser questionada sua eficiência para o aprendizado da leitura devido ao fato de que a confiança excessiva no conhecimento prévio do leitor podia promover construções inadequadas de sentido e revelar falta de conhecimento das estruturas de uma língua.

Valorizando agora a interação entre texto e leitor, teremos o modelo sociopsicolinguístico, proposto pela Psicologia Cognitiva, que voltou sua atenção para a relação entre o conhecimento de mundo que o leitor mobiliza durante a leitura e compreensão de um texto.

\subsection{O modelo sociopsicolinguístico}

Ler, em uma perspectiva sociopsicolinguística, é saber utilizar com destreza as habilidades de decodificação e encaminhar ao texto os objetivos, as ideias e as experiências de mundo do leitor, considerando que, para a eficiência da leitura, é necessário o envolvimento do leitor em um processo de previsões e inferências que se apoiam nas informações proporcionadas pelo texto e na bagagem do leitor enquanto alguém historicamente situado. Também se espera que o leitor seja um processador ativo do texto e que a leitura se constitua em um processo constante de emissão e verificação de hipóteses que geram a construção do texto e do controle de tal compreensão. 
Sem privilegiar o texto ou o leitor, este modelo acredita que a construção dos sentidos de um texto ocorre por meio de um processo ativo e dinâmico entre o autor e o leitor via texto, portanto, atrelado à compreensão dos elementos sociais,

Esse fluxo de informação presente no modelo sociopsicolinguístico de leitura mostra, segundo Cicourel (1974), que as informações não estão cristalizadas no texto, que somente oferece pistas indiciais para o leitor que, para serem transformadas em informações, precisam do uso dos vários níveis de conhecimento do leitor, inclusive o linguístico.

Para Grabe e Stoller (2002), a compreensão de um texto ocorreria de duas formas: primeiramente, utilizando-se de um processo cognitivo de nível baixo, que se refere ao acesso lexical, no qual o reconhecimento do significado da palavra leva a uma formação semântica das informações do texto; e depois em um processo cognitivo de nível alto, formado pela interpretação das ideias do texto, no qual estabelecemos os propósitos de leitura, acionamos nosso conhecimento prévio, monitoramos e avaliamos as informações lidas.

Para os autores (op. cit.), a ideia principal deste modelo é a da interação entre os modelos bottom-up e top-down no processo de compreensão leitora, já que para se fazer uma leitura, o reconhecimento das palavras precisa ser rápido e eficiente, assim como as previsões que o leitor faz do que irá aparecer no texto.

Os livros didáticos que trabalham este modelo de leitura abordam questões inferenciais e globais, consideradas por Marcuschi (2003) as mais complexas, pois exigem conhecimentos textuais, pessoais, contextuais, enciclopédicos e o uso de inferências. Como exemplo, temos as perguntas do tipo "Levando-se em conta o sentido global do texto, podemos concluir que...". Assim, é considerado um leitor proficiente aquele que lê as entrelinhas e realiza atividades de geração de sentido pela união de várias informações.

A incorporação do contexto na atividade de leitura permite, segundo Eco (1997), considerar a intenção de um texto como uma fonte de significados que, apesar de não se reduzir à intenção do autor, restringe as várias interpretações do leitor. Esta postura de Eco (op. cit.; p.28) critica as teorias que supervalorizam o leitor. O autor (op. cit) chamou de superinterpretação as leituras que ignoram os sentidos propostos pelo autor, já que as palavras são um conjunto um tanto embaraçoso de evidências materiais que o leitor não pode deixar passar em silêncio, nem em barulho. 


\section{Procedimentos Metodológicos}

\subsection{Os sujeitos da pesquisa}

Os sujeitos que participaram desta pesquisa foram 50 professores, sendo 25 em formação inicial e 25 em formação continuada, que estudam|trabalham em instituições públicas de ensino da capital cearense.

\subsection{Procedimentos da coleta do corpus}

Utilizamos a entrevista como um instrumento de pesquisa por acreditarmos que ela é um procedimento metodológico importante para a análise dos dados, também porque o diálogo mantido com os sujeitos envolvidos neste trabalho nos permitiria que fossem relatados fatos e ações por eles vivenciados em suas práticas de leitura em sala de aula, e fora dela, além do fato de que conversar pessoalmente com os professores favoreceria a complementação de algumas perguntas.

A análise dos dados foi feita de forma quantitativa e qualitativa. Este último tipo de análise dos dados se fez necessário porque, segundo Eisner (1991), permite que o pesquisador, dentre tantas vantagens, interprete qual o significado de uma situação para os sujeitos da pesquisa e veja as particularidades de cada contexto.

A fim de preservar a identidade dos sujeitos-informantes, quando nos referirmos a eles ao longo da análise dos dados, os identificaremos pelas siglas PFI (Professores em Formação Inicial) e PFC (Professores em Formação Continuada) e pelos números de 1 a 25.

A seguir, iniciaremos a análise dos dados.

\section{A leitura na sala de aula ou o porquê de concepções tão diferentes...}

O resultado das entrevistas com os professores nos mostrou que para os professores em Formação Inicial a concepção de leitura predominante foi a Sociopsicolinguística ao passo que para os professores em Formação Continuada a concepção de leitura predominante foi a mecanicista, como podemos ver nos gráficos a seguir: 

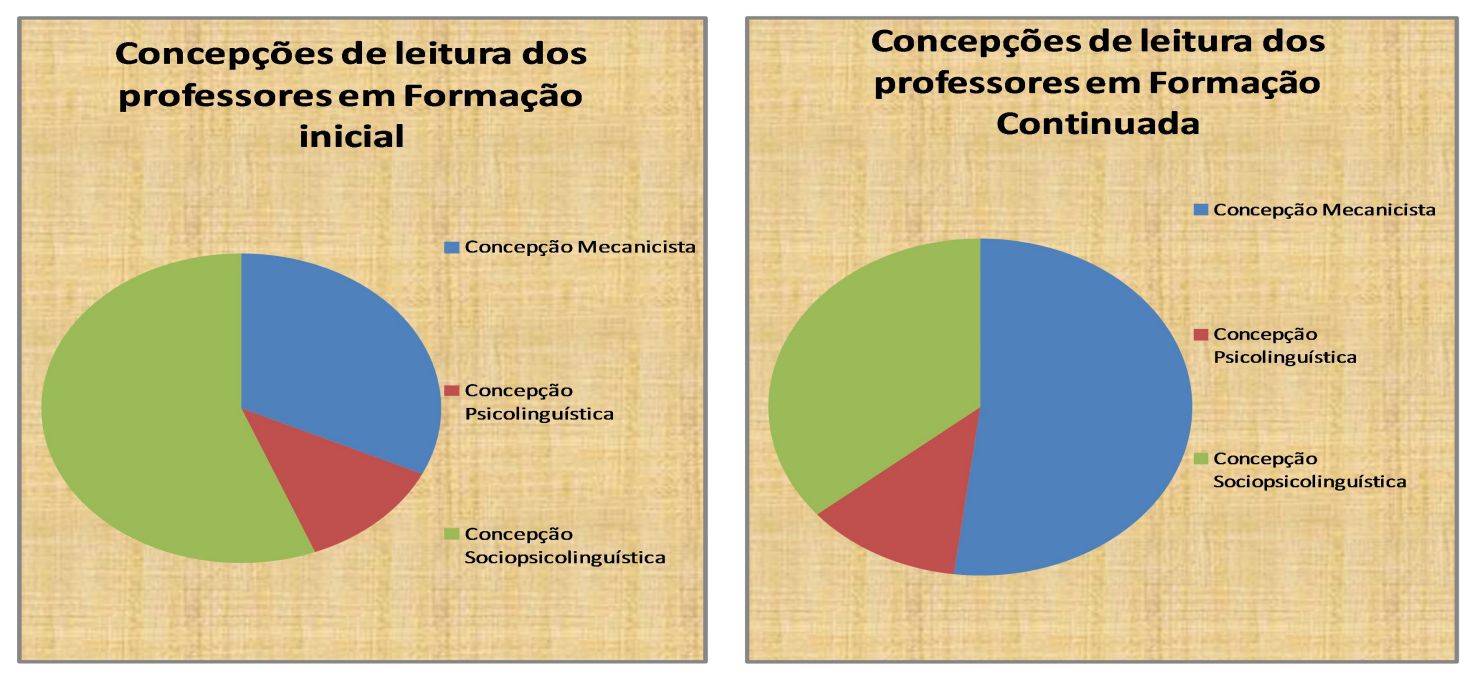

As respostas dadas pelos professores à pergunta "Para você, o que é ler?" e que se enquadram na visão mecanicista de leitura acreditam que ela é:

A) Um meio de se obter conhecimento

Ler é uma forma de o aluno se aprofundar nos conhecimentos e saber mais sobre determinado assunto das matérias escolares. (PFl15)

Ler é uma forma para os alunos se desenvolverem e aprenderem como devemos escrever as palavras corretas. (PFC18)

Interessante frisarmos a resposta de $\mathrm{PFC}_{18}$ Ler é uma forma para os alunos se desenvolverem e aprenderem como devemos escrever as palavras corretas para quem a leitura serve para escrever e falar corretamente, o que nos mostra que para este professor a leitura é tarefa apenas das aulas de Língua Portuguesa.

Notamos também que a finalidade da leitura, para boa parte dos professores em formação continuada, resumiu-se apenas a obtenção do conhecimento escolar. Nessa visão, ler tem a finalidade apenas escolar, o ler para aprender, segundo Solé (1998).

Segundo Leffa (1996), ao tomarmos o texto como material do qual absorvemos o conhecimento, estamos considerando o leitor como alguém que recebe pronto o significado do texto, o que sabemos, de todo, não ser verdade.

Enquadradas no modelo tradicional de leitura temos as respostas dos professores que creditam à leitura a tarefa inicial de decodificação, como veremos a seguir. 
O item $B$, mostrado abaixo, ilustra as respostas dos que consideram a leitura como decodificação:

B) Decodificação dos signos gráficos:

Saber reconhecer as frases, as palavras e as letras do texto ( $\left.P F I_{1}\right)$

Ler é ter uma excelente performance leitora em voz alta (PFC9)

Notamos que nestes exemplos está clara a referência à leitura como adição dos elementos que compõem um texto, desde as unidades menores (letras e sílabas) até as consideradas de mais alta complexidade (palavras, frases e textos).

A tarefa de decodificação de um texto, segundo Kleiman (1993), deve ser vista como uma etapa da leitura, não como um conceito de leitura, pois se assim o fosse, ela estaria reduzida à identificação de partes dos textos e à oralização,

Na verdade, a decodificação deve ser vista como uma espécie de mola propulsora para a compreensão leitora.

No entanto, conceber a decodificação como um conceito de leitura é ainda fruto de uma prática ainda muito presente nas aulas de português nas classes dos alunos que fizeram parte de nossa pesquisa. No dizer das professoras das salas de aula pesquisadas, principalmente as de $7^{\text {a }}$ série, a leitura em voz alta realizada ou individualmente ou coletivamente é bem mais fácil de ser controlada, ou seja, nós podemos saber, de fato, quem sabe ler.

Segundo Kleiman (1996; p.22), se o objetivo do professor é o de verificar se o aluno automatizou as correspondências grafofônicas, se conhece o valor da pontuação, a leitura em voz alta pode ser a melhor forma de avaliar esse conhecimento, no entanto, nem sempre esta atividade é necessária, sendo muitas vezes impresumível se o objetivo for ampliar o vocabulário visual de reconhecimento instantâneo, ou desenvolver os hábitos típicos do leitor proficiente.

Ainda sobre a leitura a leitura em voz alta, mencionada anteriormente, ela é uma forma de acentuar a aprendizagem da leitura enquanto uma atividade mecanizada, sem sentido e com pouco significado para o aluno. Para Kleiman (1996), se essa atividade de decifrar cadeias fônicas para os alunos não for integrada à compreensão do texto, a leitura 
terá sido subvalorizada. Além de, segundo Smith (1989), sobrecarregar, às vezes, a memória de curto termo, ocasionando a chamada visão de túnel, fenômeno que dificulta a compreensão do texto, pois o cérebro do leitor fica sobrecarregado de informação visual, efetuando a leitura de forma lenta, concentrando-se apenas na decifração. Isso aconteceria, por exemplo, se o aluno lesse cada letra de uma palavra ou se houvesse interrupção no fluxo da leitura, o que acarretaria o apagamento, ou pelo menos dificultaria, a construção do significado do texto.

Acreditamos que a leitura em voz alta, da maneira como foi posta pelas professoras, é uma retomada à aprendizagem controlada, aquela na qual se pode mensurar o conhecimento. Segundo Colomer e Camps (2002), a leitura em voz alta na escola seria bem mais aproveitada se proporcionasse o prazer da declamação de textos literários ou em situações de comunicados para os escolares, fora isso, ela não muito é eficaz.

Enquadradas no modelo tradicional de leitura temos as respostas dos professores que creditam à leitura a tarefa de memorização de informações do texto, como veremos a seguir.

C) Memorização de informações do texto:

Ler é memorizar o que a gente vê no texto. (PFl14)

Ler é ajudar o aluno a memorizar os assuntos do texto que ele vê em sala. (PFCO4)

Essa resposta nos mostra que o professor acredita na hipótese de que o bom leitor é aquele que retém mais informações do texto. Ou seja, não podemos dizer que alguém tenha entendido um texto se é capaz de repetir seus elementos de memória, na verdade, o bom leitor, quando compreende um texto, segundo Colomer e Camps (2002), explica-o com suas próprias formulações e, para fazer isso, é necessário que entenda as relações entre os componentes do texto, que serão formadas ao longo de sua leitura.

Acreditamos que esta concepção de leitura nos alunos é resultado de experiências anteriores de aprendizagem de língua e da influência de seus professores. Como consequência temos, segundo Kleiman (1996), um pseudo-leitor, um indivíduo passivo, disposto a aceitar a contradição e a incoerência, pois não percebe que seus conhecimentos de mundo e linguísticos influem de maneira direta na construção do significado do 
texto. Assim a leitura assume um caráter apenas ascendente, reduzido ao processo de decodificação das estruturas linguísticas que compõem o texto.

A menção feita anteriormente à Kleiman (1993) e Coscarelli (1999), no tocante à decodificação como uma etapa da leitura, ratifica que as atividades que poderiam levar o aluno a se tornar um leitor proficiente não ficariam comprometidas se a postura do professor diante da prática de leitura contribuísse para alterar a visão de mundo dos alunos, a fim de torná-los aptos a intervirem na sociedade, que é o objetivo maior do ensino da leitura.

Na história da leitura, segundo Possenti (2001), essa concepção corresponderia ao estágio filológico, no qual o autor é a figura central e o leitor, mero receptor de informações.

A correlação entre ler e decodificar, contudo, não é suficiente para concebermos a leitura. Há ainda os professores que acreditam na leitura como uma negociação entre o leitor e o que o texto quer dizer, como veremos a seguir.

\section{Visão psicolinguística de leitura}

Ler é pegar um livro e entender o que o texto quis dizer. ( $\mathrm{PFI} 23)$.

Ler é se concentrar somente no texto para você poder entender o que ele quis dizer. (PFC17).

As respostas que denotam uma visão psicolinguística de leitura, enumeradas acima, centraram-se na importância de descobrir o que o texto quer dizer, ou seja, em interpretálo, mas a interpretação centra-se no sentido que o leitor dá ao texto, a partir do qual este adquire significado.

Nestas respostas é nítido o enfoque na palavra você, evidenciando que é o leitor a fonte primordial de leitura de um texto. Dessa forma, o significado torna-se bastante fluido, cabendo ao leitor decidir se um texto tem ou não sentido.

Claramente distinta da concepção tradicional de leitura, nesta o leitor não é visto mais como mero decodificador, uma vez que utiliza seus conhecimentos para retirar as informações que o texto escrito pode oferecer e reconstrói o significado do texto ao interpretá-lo de acordo com seu conhecimento de mundo e com o uso de estratégias de previsão, confirmação e seleção. 
Segundo Goodman (1988) e Smith (1989), essa concepção tem o grande mérito de ver a leitura como um processo de criação, e confirmação ou não das hipóteses, a partir do conhecimento prévio sobre a língua e o mundo, assumindo, assim, um caráter descendente.

Para Martins (1992, p.17), a grande contribuição dessa concepção para os estudos da leitura foi o de perceber que

o leitor pré-existe à descoberta do significado das palavras escritas; foi-se configurando no decorrer das experiências de vida, desde as mais elementares e individuais às oriundas de intercâmbio de seu mundo pessoal e o universo social e cultural circundante.

Assim, podemos concluir que, ao lado de uma concepção de texto como produto do pensamento do autor e da língua como representação desse pensamento, há uma concepção de um sujeito de "competências", aquele que apreende o conteúdo do texto ao testar e confirmar ou não suas hipóteses de leitura.

Acreditamos que esta concepção de leitura é um grande passo para uma abordagem mais ampla sobre o que seja leitura, no entanto, ser o modelo sênior de leitura, como acreditavam Goodman (1976) e Smith (1989), é concordar com a possibilidade de creditar qualquer sentido ao texto, o que não é verdade.

De fato, possibilitar ao leitor testar hipóteses para buscar o sentido de um texto constituiu um grande passo nos estudos sobre a leitura, mas ainda não era o suficiente.

À medida que percebe a riqueza de um texto, por meio da exploração do significado, o professor-aluno começa a perceber a leitura pelo viés da interação entre autor, leitor e texto. Dessa outra concepção de leitura, trataremos a seguir.

\section{Visão sociopsicolinguística de leitura:}

Ler, para mim é interagir com textos escritos ou não escritos, formais ou não formais. (PFlo2)

Ler é gostar da leitura que você faz, por que as pessoas não vão ler só porque precisam, mas porque é bom. (PFC16) 
As respostas acima, enquadradas no modelo sociopsicolinguístico, definem, pois, a leitura sob a perspectiva da interação entre texto/autor e leitor. Nesta acepção, o processo de interação entre texto/autor e leitor ocorre mediante as marcas linguísticas presentes no texto, por meio das quais é possível ao leitor perceber a intencionalidade do autor e concordar ou não com elas.

Segundo Dell'Isolla (1996; p. 72), na interação entre texto/autor e leitor estão explícitas as marcas individuais e as determinadas pelo lugar social de onde provém o sujeito, fato que caracteriza, portanto, a situação de intersubjetividade do leitor/texto, entidades físicas necessárias para que a leitura possa ocorrer.

Acrescentaríamos, ainda, que o contexto social é o elemento que circunda a interação entre estes três elementos, pois se a leitura é uma prática social, ela assim o é porque os elementos que a compõe estão inseridos em um momento socio-histórico que determina a linguagem e o sentido.

Outra resposta que nos chamou a atenção foi a de PFlo2, Ler, para mim é interagir com textos escritos ou não escritos, formais ou não formais, eu adoro ler.

Nessa resposta podemos perceber as diversas possibilidades de leitura apontadas pelo aluno e que nos remete ao conceito de multimodalidade, conforme assinalam Kress e Van Leeuwen (1996). Para estes autores (op.cit), a linguagem é constituída de forma multimodal, o que implica na construção de sentidos advinda de uma relação estabelecida entre os diversos modos utilizados para sua constituição. Desse modo, seria insuficiente uma leitura que se centrasse apenas nos aspectos linguísticos de um texto, já que a comunicação é plural e constituída de uma infinidade de modo realizacionais, condição que exige da escola novas formas de trabalho com o material escrito.

Para Martins (1992), a interação entre a linguagem verbal e a não-verbal adquire importância fundamental devido às possibilidades de complementação cada vez maiores, daí a importância da valorização da leitura não-verbal na escola, uma vez que esta restringe a noção de leitura a um processo racional de atribuição de significado à palavra escrita.

\subsection{A leitura para o professor: o que diz a prática?}

A seguir, apresentaremos análise de uma prática de sala de aula de uma professora em formação continuada, a da $7^{a}$ série, e de uma professora em formação inicial, a da $9^{a}$ série. 


\subsubsection{A leitura na $7^{\mathrm{a}}$ série: entre a canção e a colocação pronominal}

A aula da $7^{\text {a }}$ série iniciou-se com a professora dando bom dia e pedindo aos alunos que fizessem silêncio, em seguida, ela me apresentou à turma. Sentei lá atrás e comecei a fazer minhas anotações sobre as aulas.

Os dois dias de aulas que assistimos tiveram como conteúdo a interpretação de texto das músicas Deixa a vida me levar e Devolva-me, além do conteúdo colocação pronominal, explorado nos mesmos textos.

A professora distribuiu a atividade xerocada, como podemos ver abaixo, para os alunos, a fim de que eles pudessem ouvir as músicas:

Escola de Ensino Fundamental e Médio

Professora:

Aluno:

Atividade de classe

Assunto: Interpretação de texto e colocação pronominal

Deixa a vida me levar Zeca Pagodinho (Sérgio Meriti/ Eri do Cais)

Eu já passei por quase tudo nessa vida

Em matéria de guariba espero ainda a minha vez

Confesso que sou de origem pobre

Mas meu coração é nobre

Foi assim que Deus me fez

E deixa a vida me levar (vida leva eu)

Deixa a vida me levar (vida leva eu)

Deixa a vida me levar (vida leva eu)

Sou feliz e agradeço por tudo que Deus me deu

Só posso levantar as mãos pro céu

Agradecer e ser fiel ao destino que Deus me deu

Se não tenho tudo o que preciso

Com o que tenho vivo

De mansinho, lá vou eu

Se a coisa não sai do jeito que eu quero

Também não me desespero

O negócio é deixar rolar

E aos trancos e barrancos, lá vou eu

E sou feliz e agradeço por tudo que Deus me deu

E deixa a vida me levar (vida leva eu)

Deixa a vida me levar (vida leva eu)

Deixa a vida me levar (vida leva eu)

Sou feliz e agradeço por tudo que Deus me deu 
1. Quem são os compositores da música?

2. Sublinhe no texto palavras que você desconheça e consulte o dicionário a fim de encontrar seu significado.

3. Retire do texto uma passagem que mostre a classe social que o autor pertence.

4. No texto, o que o autor quis dizer no verso "Deixa a vida me levar".

5. E você, prefere deixar a vida te levar? Dê sua opinião.

6. Dê o caso dos pronomes em destaque.

7. Dê a função sintática desses pronomes.

8. Onde no texto o autor revela conhecer o uso do pronome oblíquo?

9. Na sua opinião, as "incorreções" revelam desconhecimento da modalidade escrita?

10. Se o autor tivesse seguido rigorosamente as regras gramaticais, o sentido da música seria o mesmo? Por quê?

\section{Devolva-me}

Adriana Calcanhoto (Lílian Knapp e Renato Barros)

Rasgue as minhas cartas

E não me procure mais

Assim será melhor, meu bem

O retrato que eu te dei

Se ainda tens não sei

Mas se tiver devolva-me

Deixe-me sozinho

Porque assim eu viverei em paz

Quero que sejas bem feliz

Junto do seu novo rapaz

Rasgue as minhas cartas

E não me procure mais

Assim vai ser melhor, meu bem

$O$ retrato que eu te dei

Se ainda tens não sei

Mas se tiver devolva-me

1. Quem são os compositores da música?

2. Qual sentimento esta música retrata?

3. Por que o título não se chama "Me devolva" e sim, "Devolva-me", com o pronome posposto ao verbo?

4. Observe os contextos em que ocorrem os pronomes oblíquos e tente formular algumas hipóteses para seus usos.

5. Compare o emprego dos pronomes nas músicas, observando o estilo musical, o público alvo, a época e o contexto no qual elas foram compostas?

Após escutarem as músicas, a professora iniciou a exploração da música 1, Deixa a vida me levar. Ela perguntou aos alunos qual o assunto da música e, em seguida, pediu logo 
que eles respondessem as questões do exercício. Essa tarefa levou 45 minutos para ser realizada.

A professora começou a realizar a correção oral do exercício, pedindo que um aluno, apontado por ela, dissesse qual era sua resposta e assim ocorreu nas demais questões.

O que nos deixava bastante incomodados com esse tipo de aula era a pressa da professora em terminar logo a correção da atividade, por conta do tempo, o que acabou por comprometer o trabalho com o gênero em estudo.

Acreditamos que se a música tivesse sido trabalhada, enfatizando seus aspectos composicionais, o que envolve o funcionamento do gênero e as diversas possibilidades de uso da linguagem, o trabalho de leitura teria sido bem eficaz, pois, do jeito que a atividade foi apresentada, interpretação de texto e gramática aparecem como elementos que não se cruzam na formação do texto.

Ao observarmos as questões de 1 a 5 da música "Deixa a vida me levar", as questões enfocam apenas os níveis literal e crítico da leitura, reduzindo, assim, o trabalho da leitura a cópia e aos achismos.

Nas questões 6, 7 e 8, o texto é usado como pretexto para o ensino da gramática normativa, de cunho puramente metalinguístico.

Perini (1996) acredita que essa abordagem da gramática ainda pode suscitar problemas maiores, como o fato de apoiar o ensino de Língua Portuguesa apenas na gramática normativa, fazendo com que ela se torne uma espécie de porto seguro, de caminho menos trabalhoso no trabalho em sala de aula.

$\mathrm{Na}$ verdade, o que se deve esclarecer é que o trabalho com a gramática não foi abolido, o que se espera é uma trabalho contextualizado.

Em relação à outra música, ela só foi trabalhada no segundo dia de aula.

No segundo dia de aula, a professora iniciou a aula com a chamada e logo pediu aos alunos que fizessem silêncio, pois eles iriam continuar a tarefa da aula da aula passada. Ao escutarem a música Devolva-me, as meninas ficaram bastante agitadas, comentando entre si as vezes em que elas terminaram seus namoros.

Após escutarem a música, a professora fez uma breve discussão oral do texto, enfocando as brigas de casais, o término dos namoros, para adolescentes, um assunto bastante interessante. Em seguida, os alunos foram orientados a responderem as questões referentes ao texto. 
Nas questões referentes à interpretação da música Devolva-me, vimos questões elaboradas, cujo foco são os níveis de leitura literal "Quem são os compositores da música?" (Questão 1) e interpretativo "Qual sentimento esta música retrata?" (Questão 2).

Observamos ainda uma tentativa de estabelecer uma relação mais estreita entre o texto e a gramática. Nas perguntas 4 "Observe os contextos em que ocorrem os pronomes oblíquos e tente formular algumas hipóteses para seus usos." e 5 "Compare o emprego dos pronomes nas músicas, observando o estilo musical, o público alvo, a época e o contexto no qual elas foram compostas?", podemos ver a preocupação da professora em mostrar aos alunos a importância dos diversos usos da língua, por meio da comparação dos estilos das duas músicas.

Aos estudos de língua interessam justamente esses aspectos. Em vez de um mero reconhecimento de categorias ou de classificações, tomados até então como um fim em si mesmo, importa mais observar como certas escolhas linguísticas, feitas dentro do leque de coerções da língua e do estilo pessoal, participam da construção do sentido do texto.

Certamente, nem todo texto serve para qualquer fim. A presença constante ou mesmo a ausência de determinados recursos linguísticos devem ser os critérios básicos para a escolha dos textos.

Segundo Costa (2002; p.119), o professor, ao escolher o gênero canção, deve ter em mente não só a exploração da letra, mas também dos aspectos melódicos que compõem esse texto, a fim de propiciar ao aluno uma educação de sentidos e de percepção crítica, que proporcione, ao lado do prazer sensorial e estético, um exercício de leitura multissemiótica.

Ao observarmos o professor em sala de aula, podemos, segundo Bronckart (2006; p. 207), analisar seu trabalho levando-se em consideração não apenas no domínio que ele apresenta sobre o programa, os conteúdos que devem ser ensinados e o conhecimento das reais capacidades e limitações cognitivas dos alunos; mas, principalmente (...) na capacidade de conduzir seu projeto didático, considerando múltiplos aspectos (sociológicos, materiais, afetivos, disciplinares, etc.), frequentemente subestimados e que, entretanto, constituem o 'real' mais concreto da vida de uma classe, (BRONCKART, 2006; p. 227).

Nestas observações de aula, notamos que o professor tinha um excelente domínio de três elementos, o programa, os conteúdos que devem ser ensinados e o conhecimento das reais capacidades e limitações cognitivas dos alunos, mas não nos deixou transparecer a construção do seu projeto didático, em uma situação de trabalho real, aquela que mostra a 
atividade do professor em sala de aula, a aula em si, talvez porque pense que o trabalho docente deve ser de um eminente transmissor de conteúdos.

As situações de aula observadas nos revelaram que faltou uma voz metodológica (CICUREL, 1996), uma voz que modificasse os conhecimentos dos alunos oferecendo-lhes desafios por meio de situações didáticas diversificadas e desafiadoras.

Encerradas as observações das aulas da $7^{\text {a }}$ série, vejamos, então, como foram as aulas na ga série.

\subsubsection{O gênero curriculum vitae}

Nos dois dias de aula que assistimos da 8a série, a professora não utilizou o livro didático e sim um material xerocado. O conteúdo deste material era um exemplar do gênero currículum vitae.

No primeiro dia de aula que assistimos, a professora iniciou a aula fazendo uma predição com os alunos: perguntou se eles sabiam o que era um currículum, se já haviam elaborado algum, qual o objetivo de se fazer um currículum, etc. Esse momento durou cerca de 30 minutos e os alunos participaram bastante.

Em seguida, a professora projetou duas imagens, cujo objetivo era discutir com os alunos o que poderia ser adequado ou inadequado em situações de busca de emprego, como podemos ver a seguir:

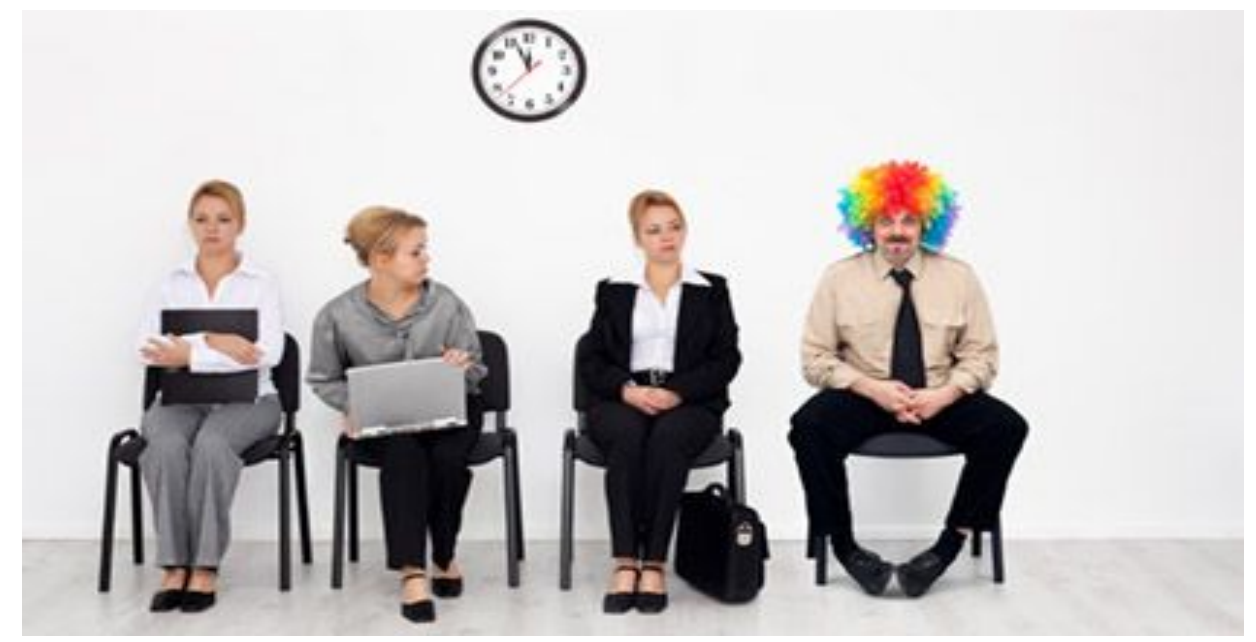

Figura 1: Captada de http://pt.wix.com/blog/2012/11/entrevista-de-emprego-como-sepreparar-para-a-segunda-fase. 


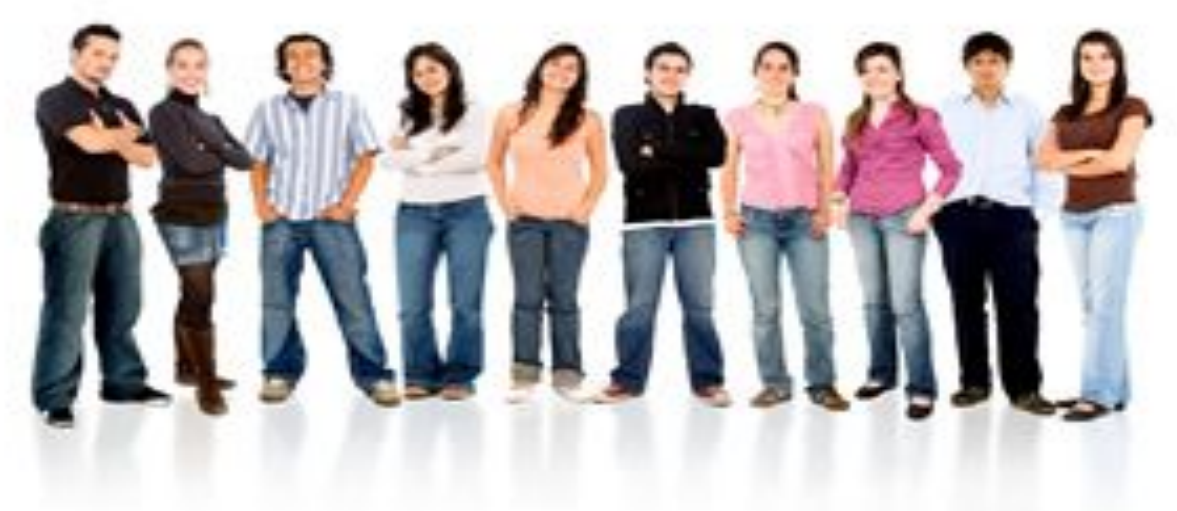

Figura 2: Captada de http://www.mulherebeleza.com/saiba-como-se-vestir-em-umaentrevista-de-emprego.html

Achamos bem interessante essa abordagem, pois além de a professora indagar os alunos sobre os locais onde eles poderiam procurar um emprego ou um estágio, deu-lhes a oportunidade de realizar uma leitura das imagens.

Essa atenção dada ao texto-imagem nos mostrou a importância que a professora confere aos diferentes tipos de leitura e que concorrem para formação do sentido, pois segundo Goulemot (1996; p.108), o sentido do texto é também produto de sua fisiologia.

A leitura de textos verbais e não verbais propiciou aos alunos ampliar as possibilidades de leitura e estimula-os a fazer relações da imagem com cenas do cotidiano. Isso ocorreu quando a professora pediu que os alunos observassem os personagens e dissessem como eles estavam vestidos, qual comportamento se espera de um candidato a uma vaga no mercado de trabalho, dentre outros aspectos que se deve verificar quando um candidato se submete a uma vaga de trabalho.

Essa forma de a professora trabalhar os dois textos, o verbal e o não verbal, expande, segundo Kress (2003), a concepção de letramento que, para o autor, não se restringe à leitura ou à escrita de materiais impressos, mas inclui a leitura de todos os meios semióticos.

O sinal tocou, às 20 horas, e assim encerrou nosso primeiro dia de observação na sala de aula da ga série.

No segundo dia de aula, a professora trabalhou com notícias sobre o mercado de trabalho e com um vídeo que mostrava dicas para uma entrevista de emprego. 
Tais materiais seriam importantes, segundo a professora, porque na sexta-feira um funcionário de uma grande rede de supermercado viria à escola conversar com a turma sobre uma seleção para diversos cargos dentro da empresa.

Nesta aula, os alunos participaram bastante, fazendo perguntas e mostrando a professora suas preocupações sobre o futuro profissional.

Pelas observações de aula da $9^{a}$ série, pudemos perceber as diversas simbioses realizadas em uma situação de trabalho real: o professor coordena o conhecimento do programa, dos conteúdos a ser ensinados e das reais capacidades e limitações cognitivas dos alunos, mas, principalmente, a capacidade de conduzir seu projeto didático, considerando o contexto real de uso do gênero textual trabalhado, no caso o currículo vitae e os elementos linguísticos e discursivos que compõem este gênero, e o valorizando o que constitui o real mais concreto da vida de uma classe (BRONCKART, 2006; p. 227)

Acrescentamos também outro fator responsável pela abordagem de leitura mais produtiva: a participação, o interesse dos alunos pelas aulas. As salas de aula que tiveram um melhor trabalho com a leitura tinham alunos conscientes da importância do estudo na vida deles. Acreditamos que a parceria professor-aluno é uma ferramenta primordial para um melhor desempenho no ensino-aprendizagem.

A leitura da forma como foi trabalhada nas aulas da $9^{\text {a }}$ série revela o trabalho real de um professor que olha para si mesmo e observa que a sala de aula deve ser, a medida do possível, um continuum com o ambiente que a cerca. Para Cicurel (2001), o trabalho do professor deve ser o de oferecer ao aluno a pluralidade de mundos de leitura.

\section{Terminando, pelo menos, por enquanto....}

Acreditamos que a leitura na escola ainda precisa de muita reformulação, ainda é necessário torná-la um objeto, sobretudo, social, um pouco mais livre do tratamento, cristalizado, avaliativo e quantificativo dado pela escola, afinal, tudo muda, o tempo todo, no mundo. Não cabe mais à escola, em pleno século XXI, ser um abismo entre as necessidades escolares e as sociais. Certas de que a leitura deve ser um objeto de discussão antes, durante e depois de seu processamento, estamos convictas de que ela não pode ser vista apenas como um produto acabado e suficiente em si, mas como uma habilidade que permite aos indivíduos uma gama de aberturas para o convívio social.

Ao analisarmos as concepções e práticas de leitura de professores em formação inicial e continuada, esperamos ter estabelecido um panorama sobre a profissão do 
professor, na tentativa de compreendermos e explicarmos os fatores que determinam uma ou outra proposta de ensino, tal intuito, conforme Clot e Faïta (1999) e Clot (2006), é para que possamos auxiliar o trabalhador docente a desempenhar suas funções de forma eficiente e ergonomicamente eficaz.

Pensar o trabalho docente desta forma nos leva a analisar as condutas humanas como ações significantes, ou como ações situadas, cujas propriedades estruturais e funcionais são, antes de mais nada, um produto da socialização (BRONCKART, 2003, p.13), objetivo, acreditamos, precípuo da escola.

\section{Referências}

BRAGGIO, S.L.B. Leitura e Alfabetização: da concepção mecanicista à sóciopsicolingüística. Porto Alegre: Artes Médicas, 1992.

BRONCKART, J.P. Atividade de linguagem, textos e discursos: por um interacionismo sociodiscursivo na escola. São Paulo: EDUC, 2003.

Atividade de linguagem, discurso e desenvolvimento humano. Campinas: Mercado de Letras, 2006.

CHARTIER, R. Do livro à leitura. In: CHARTIER, R. (Org). Práticas da leitura. São Paulo: Estação Liberdade, 2001.

CICOUREL, A. Cognitive sociology: language meaning in social interaction. New York: Free Press, 1974 .

CICUREL, F. L'instabilité énonciative en classe de langue. In: Les Carnets du Cediscor [En ligne], vol.4, 1996. Captado de http://cediscor.revues.org/393. Acesso em o1 junho de 2015.

CICUREL, F. Quand le français langue professionnelle est l'objet de l'interaction. In: Les Carnets du Cediscor [En ligne], vol. 7, 2001. Captado de http://cediscor.revues.org/297. Acesso em o1 junho de 2015.

CLOT, Y; FAÏTA, D. Genres et styles en analyse du travail. Concepts et méthodes. Travailler, 6, 7-43, 1999.

A função psicológica do trabalho. Petrópolis: Vozes, 2006.

COLOMER, T. ; C. A. Ensinar a ler, Ensinar a compreender. Porto Alegre: Artmed, 2002. 
COSTA. N. B. da. As letras e a letra: o gênero canção na mídia literária. IN: DIONÍSIO, A.P.; MACHADO, A.R. e BEZERRA, M.A. (Orgs.) Gêneros textuais e ensino. Rio de Janeiro:

Lucerna, 2002.

CURTO, L. et al. Escrever e ler: como as crianças aprendem e como o professor pode ensiná-las a escrever e ler. Porto Alegre: Artmed, 2000.

DELL'ISOLLA, R. L. P. A interação sujeito-linguagem em leitura. In: MAGALHÃES, I. (org.) As múltiplas faces da linguagem. Brasília: UNB, 1996.

ECO, U. Interpretação e superinterpretação. São Paulo: Martins Fontes, 1997.

EISNER, E.W. The enlightened eye: qualitative inquiry and the enancement of educational practice. New York: Macmillan Publish Company, 1991.

GOODMAN, K. The reading process. In: In: CARREL, P.L. DEVINE, J. ESKEY, D.E. (eds.). Interactive approaches to second language reading. Cambrigde: Cambrigde University Press, 1988, p.11-21.

GOULEMOT, J. M. Da leitura como produção de sentidos. In: CHARTIER, Roger (Org.).

Práticas de leitura. São Paulo: Estação Liberdade, 1996.

GRABE, W. ; STOLLER, F. L. Teaching and researching reading. London, England: Pearson Education, 2002.

KLEIMAN, A. Oficina de leitura - teoria e prática. Campinas: UNICAMP, 1993. . Leitura: ensino e pesquisa. Campinas: Pontes, 1996.

KRESS, G. ; VAN LEEUWEN.T. Reading Images: The Grammar of Visual Design. London: Routledge, 1996.

KRESS, G. Literacy in the New Media Age. London: Routledge, 2003.

LEFFA, V.J. O conceito de leitura. In: Aspectos da Leitura: uma perspectiva. Psicolinguística. Porto Alegre: Sagra, DC Luzzatto, 1996. p. 9-18.

LEURQUIN, E. V. L. F. Contrato de comunicação e concepções de leitura na prática pedagógica de língua portuguesa. UFRN: Natal, 2001. Tese de Doutorado.

MARCUSCHI, L. A. Compreensão de texto: algumas reflexões. In: DIONÍSIO, A. e PAIVA, M. A. O livro didático de português: múltiplos olhares. Rio de Janeiro: Lucerna, 2003.

MARTINS, M. H. O que é leitura? São Paulo: Brasiliense, 1992.

PERINI, M. A.. Gramática descritiva do português. São Paulo: Ática, 1996.

POSSENTI, S. Sobre a leitura: o que diz a Análise do Discurso? IN: MARINHO, M. (org.). Ler e navegar: espaços e percursos da leitura. Campinas: Mercado de Letras, 2001, pp. 19-30. 
SAMUELS, S. J. \& KAMIL, M. Models of the reading process. In CARRELL, P.L; DEVINE, J. ESKEY, D.E.(eds.). Interactive approaches to second language reading. Cambridge: Cambridge University Press, 1988.

SCARAMUCCHI, M.V.R. O papel do léxico na compreensão em leitura em língua estrangeira: foco no produto e no processo. Tese de Doutorado. Campinas: Unicamp, 1995.

SMITH, F. Compreendendo a Leitura: uma análise psicolingüística da leitura e do aprender a ler. Porto Alegre, Artes Médicas, 1989.

SOLÉ, Isabel. Estratégias de Leitura. Porto Alegre: Artmed, 1998.

\footnotetext{
' Monica Sousa SERAFIM - Doutora em Linguística e Professora do Curso de Letras e do Programa de PósGraduação em Linguística da Universidade Federal do Ceará. Email: mserafim15@gmail.com
} 